\title{
DIGITALCOMMONS
}

$1-1-2008$

\section{Real World Projects in an Advanced Instructional Design Course}

Monica W. Tracey

Wayne State University, Monicatracey@wayne.edu

Christina Chatervert

Oakland University

Kristy Lake

Oakland University

Robert Wilson

Oakland University

\section{Recommended Citation}

Tracey, M. W., Chatervert, C., Lake, K., \& Wilson, R. (2008). Real world projects in an advanced instructional design course. TechTrends, 52(4), 24-29.

Available at: http://digitalcommons.wayne.edu/coe_aos/11 
Real World Projects in an Advanced Instructional Design Course

\author{
Monica W. Tracey \\ Christina Chatervert \\ Kristy Lake \\ Robert Wilson \\ Oakland University
}




\section{Real World Projects in an Advanced Instructional Design Course Monica W. Tracey, Christina Chatervert, Kristy Lake, and Robert Wilson Introduction}

This design case focuses on the redesign of Advanced Instructional Design, a capstone course taught in a Midwestern university's Masters of Training and Development program. The goal of the course was to have students integrate knowledge and skills from previous courses including needs assessment, introduction to instructional design and program evaluation. Historically, this integration process included case studies in instructional design and the design and development of a simulated instructional project. This article documents the process and outcomes of the course redesign incorporating a real world project from the instructor's perspective and reflections from four of the graduate students participating in this experiential course.

Applying the principles of instructional design in a classroom simulated environment is unlike applying the same principles with a client, a deadline, and all of the constraints inherent in the process. Providing students with as close to a real world design experience as possible in one semester with a client willing to allow students into their company appeared unfeasible. Studies however, comparing two groups of designers, one in a business setting and the other in a university setting (Kirschner et al, 2002) indicated each group differed in their design focus, specifically on how they analyzed alternative solutions, and on their interaction and involvement with the client. As the faculty member 
teaching the course, my goal was to provide students with an experience that closely mirrored designing in a business setting.

This course has been a part of the curriculum since the program's inception, with the goals remaining constant. Defining instructional design, analyzing the steps including needs assessment, goals and objectives, instructional strategies, evaluation and assessment are critical to all instructional designers. The question for me as the new instructor was how to assure students achieved these goals while giving them an experience closely emulating real world instructional design? I decided to redesign the course to include an instructional design project with a client, design groups, deadlines and deliverables. This decision began a journey affecting students, faculty, a company, and its employees.

\section{Course Development}

As stated above, the course goal and outcomes were pre-determined. In the traditional course structure, these outcomes were achievable, but adding a real world design experience meant dealing with and balancing numerous additional variables including:

1. Available class time

2. A balance in the amount of course content and additional assignments

3. A company willing to allow access to graduate students

4. The incorporation of real world knowledge, application and learning

5. Group dynamics

6. The final design products 
The remainder of this case reports on the process and results of the redesign specifically focusing on these variables. In addition, student and faculty reflections are presented.

\section{Course Content and Requirements}

Available Class Time. The duration of each class, held once per week, was approximately four (4) hours over 15 weeks. The sequence of classes (the prioritization of instructional information presented) needed to be redesigned to include the real world instructional design project. In the redesign, I allocated 30 minutes each week for teams to work on the project. Once the project began, however, the student groups needed at least one hour per week to collaborate so I had to make adjustments in the delivery of the rest of the content and strategies during the semester. Course content included adult learning, instructional design models, and assessing needs, developing goals, creating a design document and instructional strategies, creating instructional materials, designing evaluation tools, and piloting and revising a program. After a few weeks of adjusting, each class was structured as follows: introduction of class topic in an opening activity, instruction on the topic, followed by student groups practicing what they learned in the context of the project for the remainder of the class time.

Amount of Course Content and Additional Assignments. In addition to classroom attendance and learning, students were required to write a research paper with an in-depth examination of one topic pertaining to an area in instructional design. This paper accounted for 30 percent of the final grade. A take home exam was administered and accounted for 30 percent of the final grade, while the group project including the development of their course goals, objectives, design document, instructor guide and 
participant guide counted for 40 percent of their grade. The rationale behind this was to empower students in determining their own grade while still holding them accountable in their group. Upon reflection, and as a result of student feedback, neither of these assignments will be a requirement in future sections of this class. The students were completely immersed in the project and both assignments were not value added. Giving power to students for their own grade is important, and reflection papers, or other individual assignments related to the project will be used in the future.

\section{The "Lab" - Real World Application and Learning}

Finding a Company Willing to Allow Access to Students. Finding the right match with a client and our class was a challenge. I knew I needed a company with evening hours as the course was an evening class (most of the students already work full time jobs). The company had to have at least three instructional design projects one for each of the student groups, and an environment where the students would be welcome. Frequent access to management and subject matter experts was also imperative if the project teams were to succeed. Three companies were willing, but only one could be chosen. One company had a large human resource department with numerous training programs. It appeared that our class would be providing a free service to a company who already had resources. Another company had only day time hours and although they were willing, the time constraints would have put a realistic restriction on the group's ability to complete their projects. The final selection of a host company was a business called Bosco's Pizza Company, located in Warren, MI. Bosco's is a privately-owned small company (150 employees running three shifts) that manufactures wholesale pizza and Bosco's Sticks for schools, hospitals, universities and businesses. Selection of Bosco's was determined by: 
1. The receptiveness and willingness of its management and workforce associates to allow access for groups of students during normal work activities.

2. Existing opportunities to apply instructional design in three areas of the company.

3. Bosco's availability; the company ran three shifts and was therefore open in the evenings for students to visit.

4. A win/win relationship based upon the students learning more about instructional design and Bosco's receiving trainings their company did not have the resources to create.

Incorporating Real World Knowledge, Application \& Learning. There is a body of research indicating the importance of incorporating authentic problem solving strategies and collaborative learning in instructional design (Tripp, 1991, Bednar et.al. 1992, Cobb, 1994, Karagiorgi, 2005,). Many state that instructional design is a problem-solving task (Perez \& Emery, 1995) and learners are more likely to view a problem from an ownership perspective when the situations represent authenticity (Karagiorgi, 2005). This was the most significant contributing factor to the success of the project and ultimately the class. The incorporation of real world knowledge, application and learning was integrated in large part due to the client we chose. The President of the company, Vice President of Manufacturing and the head of the Human Resource Department championed this project. They worked with each student team not as students but as instructional designers. They connected them with subject matter experts, met with the teams to review materials, and provided access to the manufacturing floor and all necessary documents and resources to enable the groups to create excellent products. So, now that the company was on board, the next step was to determine the groups. 


\section{The Implementation Process and Products}

\section{Group Dynamics}

Christensen and Osguthorpe (2004) found that ID practitioners most often make instructional strategy decisions and learn about theories and trends through interaction with others. This indicates the importance group interaction plays in ID practice. In addition, they maintain that programs need to provide adequate opportunities for prospective designers to develop effective group process skills. Most graduate students wince however at the thought of a group project. The process I used to pick these groups was the result of numerous failures I encountered with other group projects. Rather than have the groups choose for themselves, or be grouped as a result of where they sat the first night of class, I decided to choose the groups ahead of time. Unfortunately I didn't know any of these students. Therefore, I established three groups comprised of four students each through detailed discussions with the faculty members who taught the introduction to instructional design and evaluation courses. They provided me with feedback regarding each student's current and past work experience in instructional design. My goal was to select students with various strengths and experience, not unlike groups of employees typically formed in a work setting who work on instructional design solutions. In addition to choosing the groups myself, I gave each group very specific rules and norms they were to follow from the beginning of the project and a strict evaluation process to be used to evaluate each group member's performance along with the entire group's performance at the end of class. These rules were:

1. As a group, decide on one leader. Whoever that person is, he/she will be the contact to me. I will only talk to this person or the entire group. 
2. One person will be nominated by the group to be the spokesperson to the client. It can be the same person as above or someone else. When communicating to the client, copy me in on all correspondence.

3. The groups are self-managed. Create norms, ground rules, etc.

4. If you have problems in the group, I will talk to the entire group to consult on how the problems may be solved. Do not have side conversations with some members as it dissolves the group dynamics.

5. Watch the terminology. Do not use our terminology with the client. When communicating to the client remember they have full time jobs and are assisting us with a class project. Be respectful of their time and their limitations.

Each group member signed a Bosco’s Pizza Company Confidential Information form agreeing to safeguard the information received by maintaining confidentiality regarding the company business. The groups were then ready to begin.

\section{The Final Design Products}

Anchored instruction emphasizes skills and knowledge in holistic and realistic contexts (Cognition and Technology Group at Vanderbilt, 1990). In these contexts, students develop useful rather than inert knowledge. In addition, anchored instruction supports complex and ill-structured problems. The three groups were each assigned a stakeholder and a "problem" or need Bosco's had developed with the input and concurrence of management personnel. A site visit was also planned prior to the start of the project. A nominal amount of basic information related to the Bosco's company's history, product and processes was supplied to each group. The groups were then tasked with the problem, given a subject matter expert and told to conduct an assessment of 
current performance, to design and develop a solution and eventually present the solution. As the faculty member, my role was to provide group coaching and mentoring. The programs were presented to Bosco's upon completion of the class. The three different problems, one assigned to each group were:

1. Bosco's employees 150 employees in various positions including line workers, shift supervisors, managers and office staff. Orientation to the company although extensive, was never formalized or consistent. Group 1 was asked to create an orientation program for all new Bosco's employees. Stakeholders: CEO and President and Director of Human Resources.

2. Although well qualified in each of their areas, members of management are required to train employees never learning how to train employees for maximum performance. Group 2 was asked to create a generic train the trainer program for all of the various management levels and responsibilities. Stakeholders: Director of Human Resources, and Vice President of Manufacturing.

3. One of the most important processes at Bosco's Pizza Company is the making of the pizza and "Bosco Sticks" dough. Employees were currently learning how to make the dough from other employees, with the process not documented or formally trained. Considered an art, the process of making of the dough needed to be documented in an effort to consistently and efficiently train employees. Stakeholder: Vice President Manufacturing.

The deliverables for the project were: 
1. A design document including, goals, objectives, general content, a complete description of the instructional strategy as it relates to the content, behavior and conditions and a complete description of the assessment for each objective.

2. An instructor guide including table of contents, instructor directions, materials checklists, icons, appropriate contents for course instruction, instructional strategies, evaluations, visual support to deliver the course.

3. A participant guide for the course that will accompany the instructor guide including appropriate content.

In addition, knowing that peer-assessment and self-assessment must be incorporated, (Karagiorgi, 2005), each group member had to write one page describing what each person including themselves did on the group project. This included roles, responsibilities, products created, etc. This was limited to one page for the entire group. Each group member had the option of writing one page describing any challenges, difficulties etc. with the group and its members. These were to be written individually and confidentially.

\section{The Student's Weigh In}

A student from each group was asked to briefly describe their group's project and if there were any benefits, challenges, and/or lessons learned.

\section{Group One's Project: Kristy's Perspective}

This was an excellent project for graduate students hoping to gain real-world experience in instructional design. The project allowed us to apply all of the concepts learned throughout the program, while working with a real client. We were able to see the project through from beginning to end, and overcome challenges along the way. I think 
the biggest challenge we faced was to overcome time constraints. This was a very large project to complete within the semester, but it also kept us focused and determined. Working in a team, however, did present some problems. We had to schedule time outside of class to divide the work and/or meet to work on the project together. We tried to divide the work at first (despite Dr. Tracey's advice not to do that) and of course it did not work very well. Dividing the work created different tones and perspectives, which did not allow the material to flow as it should. Once we overcame this challenge, the project went much smoother.

As for lessons learned, I personally feel this was the most beneficial project I worked on within the entire graduate program. This project demanded strong time management skills and the ability to create group cohesion in a real-world situation. We learned the value and significance of a detailed and thorough design document. We also learned not to expect perfection in a design project with the first try. We had to present our plans and ideas to the client several times before gaining buy-in to complete the final project. The client feedback was crucial because if we had not "checked in" throughout the project, we would have spent hours on a project that did not meet the client's needs or expectations.

\section{Group Two's Project: Christina's Perspective}

Our group focused on the development of a train-the-trainer program for the executives of Bosco’s Pizza Company. Up until the point of the project, Bosco’s employees had relied on lecture style to welcome new employees into the organization as well as train them on the various procedures within the company. Our task was to develop a generic, yet comprehensive, program that would not only discuss, but also 
model various training activities. As with any project, there were challenges with this one. We were one of two teams to meet with the stakeholders at the same time for the start of work meeting. By sharing the time, the conversation centered more on the need for a revised orientation as it was the client's top priority, rather than our train the trainer course. In addition, the project challenged us to develop interactive activities related to subjects we knew little about. We also had to work within a time constraint for the training, deciding which would be the most optimal learning areas for the participants. Regarding working in a team, we found that team work is always a benefit and a challenge. The different communication and work styles of the team increased stress levels at times. The upside was that everyone had a voice in the development and execution of the project.

The benefits of working on the client-based project were numerous. Not everyone in the class had the experience of working in a team-based environment before this project. The team setting assured a higher level of accountability, knowing that team members were counting on deadlines to be met and the level of work to be exceptional. The in class time to allow groups to meet and discuss the progression of the project was essential. We also had an enhanced realization of the integral connection between balancing what the client wanted versus what the client needed.

Looking back on my classes, this project has definitely stood apart from other in-class assignments. The major takeaway for me was learning through experience. While information is important and lays the framework for learning, it is in experiencing that information where knowledge takes place. Group Three's Project: Rob's Perspective 
I was a member in the group that developed training for dough-making at Boscos. To some degree, this was the most difficult, but also the most fun (in my opinion) of all three instructional design challenges. The existing training really was a loose "apprenticeship" where a brand new employee would watch a seasoned employee and "learn the ropes" (although it was really dough). We visited the factory both during class time, but also twice during the week and on weekends to gather the information, video, and pictures we felt we needed. Our final product was a combination of introductory activities, hard copy learner guides, a 22 minute video with chapters related to setup, two methods of dough making, and later stages of dough processing.

The benefits and challenges of this "real world" ID process was a two edged sword. We benefited from being able to develop instruction for a real manufacturing process. The challenge was that, since we were all working full time jobs, we had to carve out extra time to go to the manufacturing facility to gather our data, meet with subject matter experts, and review our progress. While it would have been much easier to simply create an instructional system based on a case study, I think we all felt that our real world experience was vastly superior. One lesson learned was that the client was not particularly impressed with our creative, opening (attention-grabbing) activity or our prelearning (or pre requisite mental modeling) activities. We followed Dr. Tracey's advice to not use formal ID language, but also learned that a client might not feel they need all of the activities we might suggest. On the other hand, the video was very positively received and proved to us that a high quality instructional video could be developed with a just a hand held video camera and a personal computer. The other obvious advantage is that we all were able to have a real life project that could build our professional resumes. 
That is a great benefit over delivering an instructional solution on a case study. Finally, while it might have been more work, the camaraderie and stories we could tell after the project provided for a much richer experience.

\section{Course Evaluation and Revisions}

\section{Student Evaluations}

At the conclusion of the course, students were asked to fill out a course evaluation in an effort to collect and consolidate their feedback and to provide suggestions for course improvement. Overall students evaluated the instruction in the course a 4.83 on a 5 point scale. Student feedback relevant to this project included comments on their increased awareness of ways to confront problems in this field (4.67), the ability to use ideas and techniques from the course to solve problems (4.75), and an increase in significant understanding and skills in the field (4.67). The student response to the project was overwhelmingly positive, but other segments of the course needed to be revised during and after its first delivery in an effort to accommodate this project.

\section{Course Revisions}

Since this was the first time the course included a real client with a real project, I needed to constantly evaluate and revise the structure of the class while the class was in session. There was never enough time. Students were working diligently, at times taking time off work to go to the client and work on the project. In an effort to assist them, I rearranged the class time to give them additional time every evening to work in their groups on the project. As stated earlier, the exam and the research paper had to be altered and in the future will be deleted altogether. Due to time constraints, the final pilot and evaluation of the instruction was done after the semester ended. In the future, 
the class will be structured to include the pilot of the course with the client before the term ends.

\section{Conclusion}

One of the successes of an instructional product is its continued effectiveness. Currently Bosco's Pizza Company is implementing all three of the instructional design projects developed in this course with improved employee performance. In an effort to be an effective instructor, self-critical reflection on what I teach and how I teach it is important. While the student's voiced the benefits and challenges of working on a real world instructional design project, I faced my own benefits and challenges documenting this experience. This course, offered in winter term 2008, will implement the changes documented through student and faculty reflection. This was a journey affecting students, faculty, a company, and its employees. This was also a journey I hope other faculty members and students will take, for the experience is one worth having.

\section{References}

Bednar, A.K., Cunningham,D., Duffy, T.M. \& Perry, J.D. (1992) Theory into practice: How do we link? In Duffy \& Jonassen (Ed.) Constructivism and the technology of instruction: A conversation. (pp.17-34). Hillsdale, NJ: Lawrence Erlbaum Associates, Publishers.

The Cognition and Technology Group at Vanderbilt. (1990). Anchored instruction and its relationship to situated cognition. Educational Researcher, 19(6), 2-10.

Christensen, T.K. \& Osguthorpe, R.T. (2004) How do instructional-design practitioners make instructional-strategy decisions? Performance Improvement Quarterly, 
17(3) pp. 45-65.

Cobb, P. (1994) Where is the mind: Constructivist and sociocultural perspectives on mathematical development. Educational Researcher, 23(7), 13 - 20.

Karagiorgi, Y. \& Symeou, L. (2005). Translating constructivism into instructional design: Potential and limitations. Educational Technology \& Society, 8(1), 17 27.

Kirschner, P., Carr, C, van Merrienboer, J. (2002) How experts designers design, Performance Improvement Quarterly, 15(4) pp. 86-104.

Perez, R.S., Emery, C.D. (1995) Designer thinking: How novices and experts think about instructional design, Performance Improvement Quarterly, 8(3) pp. 80-95.

Tripp, Steven D. (1991). Two theories of design and instructional design. In: Proceedings of selected research presentations at the annual convention of the association for educational communications and technology. 


\section{Author Biographies}

Monica W. Tracey is an Associate Professor in Instructional Technology at Wayne State University, Detroit, Michigan. Her research and teaching focuses on instructional design theory and practice, designer model use and instructional design model validation.

Christina Chateauvert is a Corporate Trainer at Flagstar Bank and is a Master of Training and Development graduate of Oakland University with a concentration in Instructional Design.

Kristy Lake is a Master of Training and Development graduate from Oakland University. She is the Senior Human Resource Representative for Webasto Roof Systems in Rochester Hills, Michigan.

Rob Wilson is a $20+$ year Sales Manager with Procter \& Gamble; he is currently a Senior Training Manager for North America Sales. He is a recent graduate of the Master of Training \& Development program at Oakland University. 